\title{
The Discovery and Development of Boceprevir: A Novel, First-generation Inhibitor of the Hepatitis C Virus NS3/4A Serine Protease
}

\author{
Anita Y. M. Howe and Srikanth Venkatraman \\ Merck Sharp \& Dohme Corp., Whitehouse Station, NJ, USA
}

\begin{abstract}
An estimated $2-3 \%$ of the world's population is infected with hepatitis $\mathrm{C}$ virus $(\mathrm{HCV})$, making it a major global health problem. Consequently, over the past 15 years, there has been a concerted effort to understand the pathophysiology of $\mathrm{HCV}$ infection and the molecular virology of replication, and to utilize this knowledge for the development of more effective treatments. The virally encoded non-structural serine protease (NS3) is required to process the HCV polyprotein and release the individual proteins that form the viral RNA replication machinery. Given its critical role in the replication of $\mathrm{HCV}$, the NS3 protease has been recognized as a potential drug target for the development of selective HCV therapies. In this review, we describe the key scientific discoveries that led to the approval of boceprevir, a first-generation, selective, small molecule inhibitor of the NS3 protease. We highlight the early studies that reported the crystal structure of the NS3 protease, its role in the processing of the HCV polyprotein, and the structural requirements critical for substrate cleavage. We also consider the novel attributes of the NS3 protease-binding pocket that challenged development of small molecule inhibitors, and the studies that ultimately yielded milligram quantities of this enzyme in a soluble, tractable form suitable for inhibitor screening programs. Finally, we describe the discovery of boceprevir, from the early chemistry studies, through the development of highthroughput assays, to the phase III clinical development program that ultimately provided the basis for approval of this drug. This latest phase in the development of boceprevir represents the culmination of a major global effort to understand the pathophysiology of HCV and develop small molecule inhibitors for the NS3 protease.

(c) 2013 The Second Affiliated Hospital of Chongqing Medical University. Published by XIA \& HE Publishing Ltd. All rights reserved.
\end{abstract}

\section{Introduction}

An estimated $2-3 \%$ of the world's population is infected with hepatitis $\mathrm{C}$ virus (HCV), hence there is a need for better understanding of the pathophysiology and treatment of HCV. ${ }^{1}$ During the late 1990s and throughout the 2000s, interferon (IFN) formed the cornerstone of treatment for HCV infection, and global efforts to optimize IFN-based treatment strategies were paralleled by basic research efforts focused on the biology of HCV and the molecular virology of its replication and infection. In 2011, with the launch of the first directacting antiviral agents, boceprevir and telaprevir, these strands of research ultimately converged.

$\mathrm{HCV}$ belongs to the Flaviviridae family of single-stranded RNA viruses. It has a genome length of approximately $9.6 \mathrm{~kb}$, which is translated into a polyprotein of 3010-3033 amino acid residues. When processed, this polyprotein generates at least 10 mature structural and non-structural viral proteins (Fig. 1A). ${ }^{2}$ The non-structural 3 (NS3) serine protease cleaves the viral polyprotein to release the non-structural proteins, which then form the viral RNA replication machinery. The NS3 protease is pivotal in the processing of the viral polyprotein, and is therefore critical for HCV replication. ${ }^{2,3}$

In this article, we review the scientific discoveries that led to the identification of the NS3 protease as a rational drug target for anti-HCV therapies. In this paper, we focus on the studies that contributed to our present knowledge of the structure and replication of HCV, and the subsequent development of boceprevir as a selective small molecule inhibitor of the NS3 protease.

Insights into the structure and proteolysis of the HCV NS3 protease: implications for drug development

\section{Structure of the NS3 protease}

The X-ray crystal structure of the NS3 protease domain (amino acids 2-180) in complex with a synthetic NS4A activator peptide was described by $\mathrm{Kim}$ and colleagues in 1997 (Fig. 2). ${ }^{4}$ The NS3/4A complex adopts a chymotrypsinlike fold with two structural domains: the C-terminal domain contains a six-stranded $\beta$-barrel with hydrophobic residues localized at the core of the barrel, and the N-terminal domain contains eight $\beta$ strands, including one contributed by the NS4A peptide. These two $\beta$-barrel domains are separated by a deep cleft that harbors the catalytic triad (His57, Asp81, and Ser139), with a geometrical arrangement similar to other serine proteases. ${ }^{5} \mathrm{~A}$ zinc ion at the C-terminal domain distal 
Howe A. Y. M.: Discovery of boceprevir

(A)
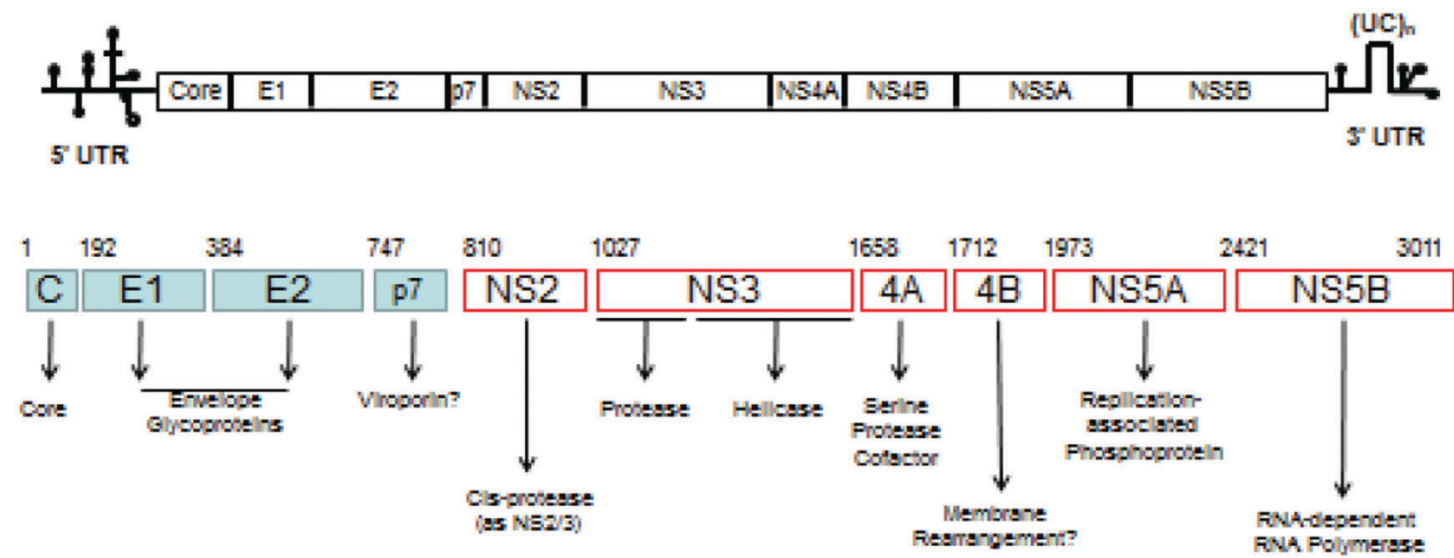

(B)

$\begin{array}{llll} & & \\ \text { NS3/4A(cis) } & \text { P-side } & \text { DLEVTT } & \frac{P^{\prime} \text {-side }}{\text { STWV }} \\ \text { NS4A/4B } & \text { DEMEEC } & \text { ASHL } \\ \text { NS4B/5A } & \text { DCSTPC } & \text { SGSW } \\ \text { NS5A/5B } & \text { EDVVCC } & \text { SMSY } \\ \text { Consensus } & \text { DXXVXC } & \text { SXXX } \\ & \text { E E T } & \text { A } \\ & & T\end{array}$

Fig. 1. HCV genome organization and biological functions. (A) Encoded gene products and (B) NS3/4A cleavage junctions. The minimal substrate required for efficient catalytic cleavage contains 10 amino acids spanning from P6 to P4'. A conserved cysteine (threonine for NS3/4A) is required at P1, an acidic residue (aspartic acid or glutamic acid) at P6, and a serine or alanine at P1'. There is a preference for valine, glutamic acid, or threonine at P3.

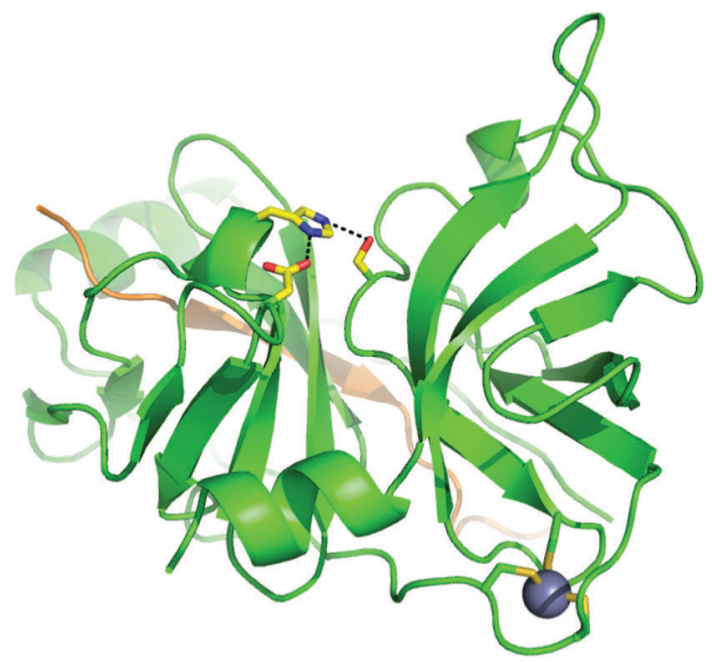

Fig. 2. Crystal structure of HCV NS3/4A. The two $\beta$-barrel sub-domains of the NS3/4A protease domain are indicated in a ribbon diagram (adapted from Protein Databank accession code 1A1R). ${ }^{4} \mathrm{His}^{57}$, $\mathrm{Asp}^{99}$, and $\mathrm{Ser}^{139}$, which form the catalytic triad are shown in ball-and-stick representation. The protease structural zinc ion (blue sphere) is indicated. The NS4A peptide is indicated as light orange. from the active site may play a structural rather than catalytic role. ${ }^{4,5}$ The crystal structure of the full-length NS3 protein molecularly linked to the NS4A peptide was solved by Yao and colleagues. ${ }^{6}$ This crystal structure provides an atomic view of the local and global structural rearrangement that involves the protease and helicase domains during polyprotein processing.

The NS4A polypeptide is believed to serve dual functions: the hydrophobic $\mathrm{N}$-terminal 20 amino acids are thought to anchor the NS3/4A complex to the host cell membrane, while the central portion provides the structural platform within one of the $\beta$-barrels of the NS3 protease domain, required for protease activation and stabilization. ${ }^{7,8}$ In the absence of NS4A, the NS3 domain is able to cleave the NS5A/B but not the NS4B/NS5A site. Co-expression of NS4A with NS3 restores the ability to cleave NS4B/NS5A, and also enhances the processing at NS5A/5B. ${ }^{9}$

\section{Biochemistry of proteolysis}

The mechanism of NS3-mediated proteolysis resembles that of other chymotrypsin-like serine proteases. Polypeptide substrates form an extended anti-parallel $\beta$ strand along the edge of the protease $\beta$-barrel, with one strand contributed by the protease and the other by the substrate. ${ }^{10}$ The catalytic amino acid triad within the active site of the enzyme orchestrates a series of covalent and acid-based catalytic 
Howe A. Y. M.: Discovery of boceprevir

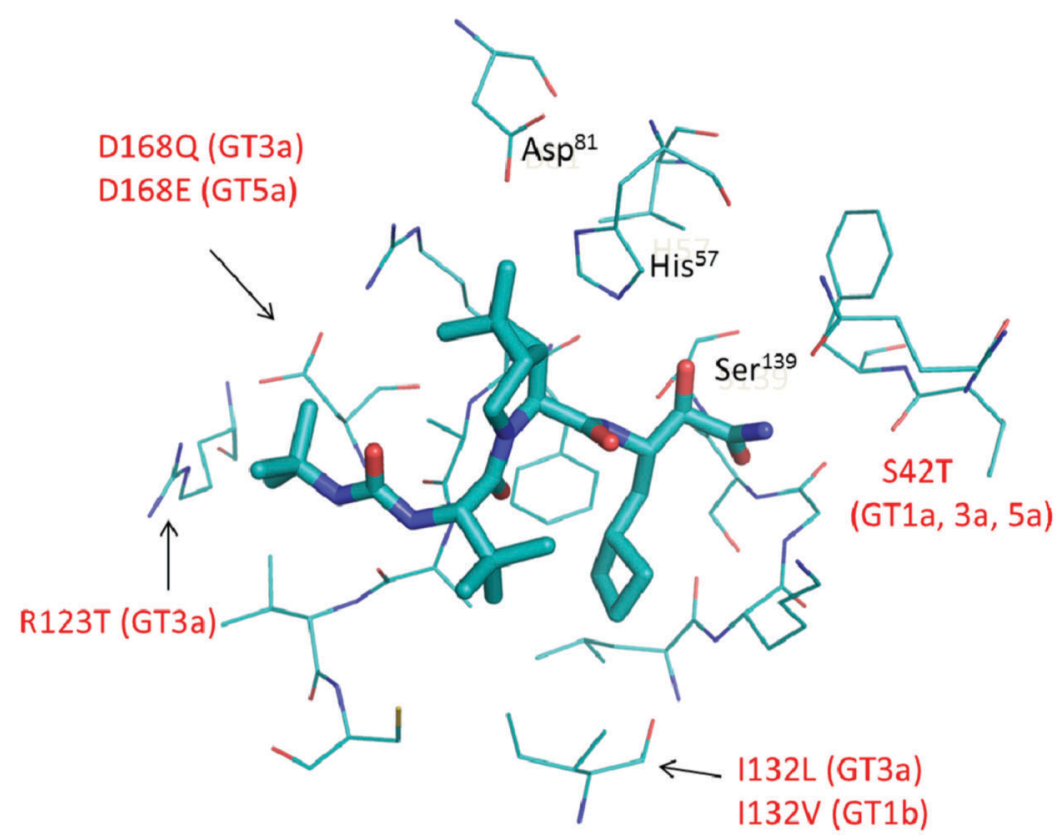

Fig. 3. Genotype (GT) diversity within the NS3/4A catalytic binding site, showing amino acid residues within $5 \AA$ of the compound/substrate binding pocket. The reference sequence is based on GT 1a (H77) [PDB 2OC8]. Asp ${ }^{81}$, His ${ }^{57}$, and Ser ${ }^{139}$ represent the catalytic triad for the NS3/4A protease. ${ }^{34}$ Residues that are not conserved between different genotypes are labeled in red. These residues have minimal impact on the binding to boceprevir.

reactions following a "ping-pong" mechanism. ${ }^{11}$ Upon binding of the polypeptide substrate to the enzyme, the nucleophilic oxygen of Ser139 in the enzyme binds covalently to the carbonyl carbon of the substrate peptide scissile bond. This requires coordination of His57 and Asp81, and results in the formation of a tetrahedral intermediate $\left(E-T_{1}\right)$, followed by release of the $\mathrm{N}$-terminus half of the peptide. During this transitional state, the negatively charged oxygen (the oxyanion) of the carboxylate tetrahedral intermediate moves to the previously vacant hole (the "oxyanion hole"), and forms hydrogen bonds with the backbone amides of Ser138 and Gly 137 , the $\mathrm{N}^{\varepsilon 2}$ of the catalytic His57, and the side chain of the Lys136. ${ }^{10}$ Dissociation of the N-terminal peptide permits binding of water and hydrolysis of the acyl-enzyme intermediate. This hydrolysis causes formation of a second tetrahedral intermediate ( $\left.\mathrm{E}-\mathrm{T}_{2}\right)$, which is again stabilized by the oxyanion hole. The final acid-base catalysis is mediated by His57 in conjunction with Asp81, releasing the C-terminus half of the peptide. ${ }^{12}$ In general, mechanism-based inhibitors exhibit a biphasic kinetic profile similar to that seen during natural proteolysis of the peptide substrates. The "inhibition" is carried out in a two-step kinetic process: the initial inhibitor-enzyme binding is followed by stabilization of the covalent interaction during the transition state.

A pivotal observation by Steinkuhler and colleagues - that the $\mathrm{N}$-terminal cleavage products of substrate peptides corresponding to the NS4A/NS4B, NS4B/NS5A, and NS5A/ NS5B are potent inhibitors of the NS3 protease - provided a key starting point in the design of peptide inhibitors and ultimately the development of small molecule compounds. ${ }^{13}$

\section{Challenges and opportunities in structure drug design}

The substrate binding site of the HCV NS3 protease is relatively shallow, solvent-exposed, and lacks the loops and other structural determinants present in other serine proteases for substrate/enzyme interactions. Several of the loops that interact with the P4, P3, and P2 moieties, and thus help to delineate a well-defined substrate-binding pocket in other serine proteases, are either shortened or missing in the NS3 protease. ${ }^{4}$ Viral substrates compensate for this shallow binding pocket with an extended substrate spanning 10 amino acid residues (P6 to $\mathrm{P} 4^{\prime}$ distal to the scissile bond) (Fig. 1B), thus allowing many hydrophobic and electrostatic interactions between protein and substrate ${ }^{a} \cdot{ }^{14}$

Based on the interactions between NS3 and viral substrates, one property of effective inhibitors may be the need for a large molecular size (the P6-P4'peptide is a decamer) to ensure substrate binding. However, large molecules complicate drug development because of their poor physicochemical properties and limited bioavailability. Therefore, it was a considerable challenge to design small molecule inhibitors with sufficient binding affinity for the shallow binding cleft of the NS3 protease, while maintaining the drug-like properties required for oral delivery.

Binding of peptide substrate appears to modulate the conformation of both the proximal region near the active site and also the distal amino acid residues, including those in the helicase domain. ${ }^{15}$ This inherent flexibility of an "induced-fit" mechanism also presents challenges for structure-based drug design. In addition, in the context of therapeutic utility, mutations that confer drug resistance can affect the favorable induced-fit binding, and thus these conformational changes can play a role in engendering viral resistance. ${ }^{16}$

\footnotetext{
${ }^{a}$ The nomenclature used here represents the residues that are $\mathrm{N}$-terminal to the scissile bond as P1, P2, P3, P4, P5, P6, and the residues C-terminal to the scissile bond as $\mathrm{P}^{\prime}, \mathrm{P} 2^{\prime}, \mathrm{P} 3^{\prime}, \mathrm{P} 44^{\prime}$. The scissile bond is located between the P1 and P1' residues, and is the site of cleavage of the substrate.
} 
HCV can be divided into six genotypes, with genotype 1 being the predominant species in North America. The genetic diversity at the NS3 active site between different genotypes presents another challenge for small molecule inhibitors (Fig. 3). Amino acid heterogeneity around the NS3 binding pocket across genotypes may mean that inhibitors exhibit vastly different potencies against different genotypes. Inhibitors with pan-genotypic activity need to be able to bypass interactions with those resides that exhibit amino acid variation.

A wealth of information on serine proteases provides insight into the mechanisms of proteolysis and the potential design of mechanism-based inhibitors. For example, one approach is to exploit the inherent binding affinity of the products released from proteolysis. An atomic view capturing the NS3-mediated cis cleavage at the NS3/4A junction showed that the NS3 C-terminal sequence, consisting of residues 626-631, forms $12 \mathrm{H}$-bonds and creates a contact surface of approximately $500 \mathrm{~A}^{2}$ near the protease active site. ${ }^{6}$ Inhibition by the P-side product corresponding to the NS4A/NS4B and NS5A/5B junctions was observed in vitro. ${ }^{17}$ These observations led to the strategy of using the $P$ or $\mathrm{P}^{\prime}$ product fragments as the scaffold for building chemical warheads/serine traps. ${ }^{18}$

\section{Biochemistry and molecular virology: translating science into molecular tools for drug discovery}

\section{Novel single-chain HCV NS3/4A protease}

NS4A forms part of the $\beta$-barrel structure of the NS3 protease, ensuring the correct alignment of the catalytic triad and hence enhancing proteolytic efficiency during polyprotein processing. ${ }^{5-7}$ During the research, various strategies were employed to generate milligram quantities of this enzyme complex in a tractable form that could be used for compound screening, biochemical studies, and X-ray crystallography. Early attempts to produce full-length $\mathrm{NS}_{1-631} / 4 \mathrm{~A}_{1-54}$ expressed in eukaryotic systems yielded relatively low quantities of active material, which was generally insoluble, making it inappropriate for biochemical and structural analyses. ${ }^{14,19}$ Expression of the $\mathrm{NS3}_{1-181}$ domain alone in Escherichia coli yielded greater quantities of protein with better solubility characteristics, but the resultant enzyme still displayed weakened proteolytic activity. ${ }^{20}$ Improved proteolytic activity was achieved by using a synthetic 12 -amino acid NS4A peptide (amino acids 22-33) in trans to complex with the NS3 protease. ${ }^{21}$ However, the overall catalytic efficiency of this enzyme remained 10 -fold lower than that of the fulllength $\mathrm{NS}_{1-631} / 4 \mathrm{~A}_{1-54 .}{ }^{21}$

The final piece in the puzzle was provided by Taremi and colleagues, who reported a single-chain construct encoding the N-terminal NS4A $\mathrm{A}_{21-32}$ fragment linked to the $\mathrm{NS}_{1-181}$ or $\mathrm{NS}_{1-631}$ protease domain through a flexible GSGS linker. ${ }^{22}$ This construct had improved solubility, and generated an active tractable reagent in sufficient quantities for compound screening and structural studies. It also allowed intercalation of the NS4A peptide into the NS3 protease domain (as suggested by the crystal structure) and resulted in a $>15$-fold improvement in the second order rate constant relative to the protease domain supplemented with a synthetic NS4A peptide. ${ }^{22}$ Overall, the NS4A $21-32$-GSGS-NS3 $3-181$ comprised approximately $5 \%$ of the intracellular protein following purification, and displayed kinetic parameters similar to those of the full-length $\mathrm{NS3}_{1-631} / 4 \mathrm{~A}_{1-54}$ generated in insect cells. ${ }^{22}$

\section{Continuous spectrophotometric enzyme assay}

The objective of the rational NS3/4A drug design program was to identify mechanism-based inhibitors that could form a stable covalent bond with the catalytic serine residue in the NS3/4A protease. The formation of this covalent bond is characterized by the slow formation of a fully reversible transition state tetrahedral intermediate. ${ }^{23,24}$ To assess potency of these "slow-binding" inhibitors accurately, it was imperative to have a continuous assay that could conveniently and accurately evaluate the time-dependent equilibrium binding of each candidate inhibitor. Traditional methods such as ELISAs or HPLC-based assays are considered discontinuous, time-consuming, and impractical for high-throughput screening. Zhang and colleagues reported a series of spectrophotometric substrates suitable for detailed continuous kinetic analyses. ${ }^{25}$ One of these substrates was a depsipeptide derived from the $\mathrm{P}$ side of the NS5A/5B junction and containing a C-terminal carboxyl group esterified with a chromophoric alcohol. This substrate was cleaved efficiently by the NS3 protease, was resistant to non-enzymatic hydrolysis, displayed adequate aqueous solubility, and allowed sensitive detection of the proteolytic product without compromising the NS3 activities. Hence, this substrate was used to develop an automated microtiter-plate assay for the rapid evaluation of candidate inhibitors. ${ }^{25}$

\section{Replicon cell-based assay of boceprevir activity}

During the initial stages of the boceprevir drug-discovery program, structure-activity relationship (SAR) studies were based primarily on enzyme assays because of the lack of a robust and reliable cell-culture system. In 1999, Lohmann and colleagues reported the first cell-culture system, using a human hepatoma cell line (Huh7) transfected with an HCV RNA derived from an infectious genotype $1 \mathrm{~b}$ isolate that contained tissue culture-adapted mutations. ${ }^{26-28}$ This replicon system was based on a subgenomic HCV RNA encoding the non-structural HCV proteins. Transfection of this replicon RNA into Huh7 cells resulted in an autonomous viral replicon without the production of infectious viruses, making it an ideal tool for inhibitor evaluation. The replicon system was adapted into a 384-well format for high-throughput screening of small molecule inhibitors.

\section{Discovery of boceprevir: a novel HCV NS3 protease inhibitor}

\section{Chemistry}

The search for a small molecular inhibitor of the HCV NS3 protease began by screening compound libraries. Traditional high-throughput screening of compound libraries failed to identify chemical leads that could be followed-up by optimization of medicinal chemistry structure activity. Given no viable lead from screening, a structure-based design approach was adopted. The first compounds synthesized were based on an HCV protease substrate, incorporating reversible electrophilic traps that could potentially bind covalently to catalytic Ser139. Introducing a ketoamide moiety generated an undecapeptide (Analog 1) (Fig. 4) that inhibited NS3 enzyme activity at low nanomolar concentrations $\left(K i^{*}=1.9 \mathrm{nmol} / \mathrm{L}\right)$.

However, this lead compound lacked almost all the desired drug-like characteristics, and was unsuitable for clinical 

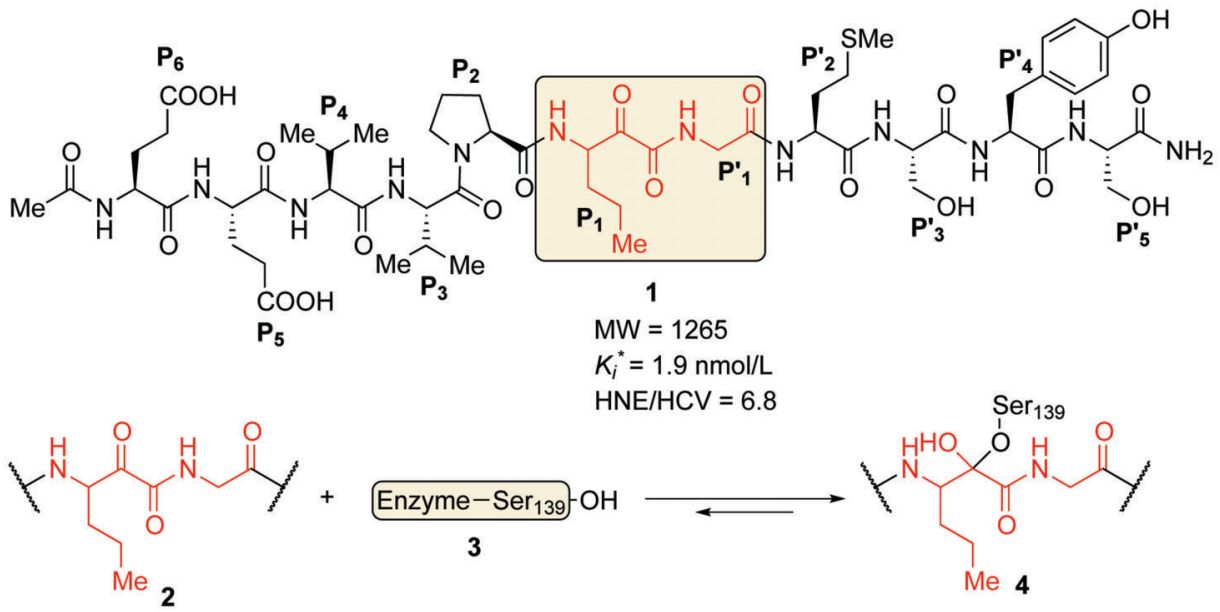

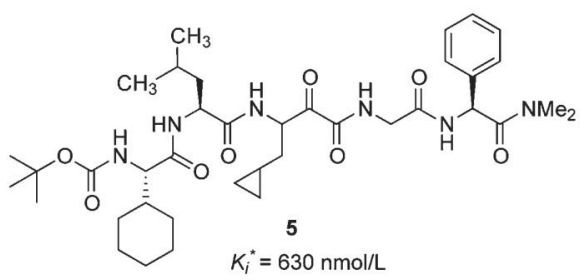

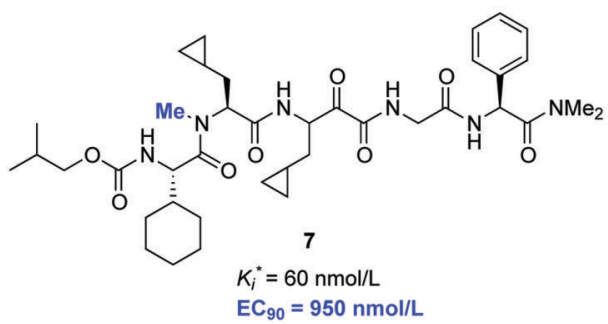

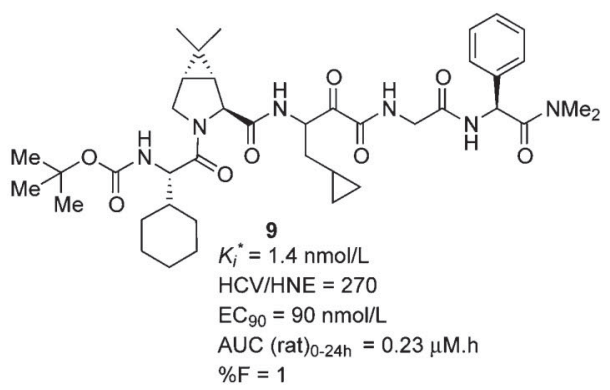

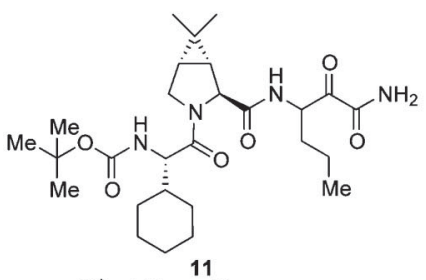

$K_{i}^{*}=100 \mathrm{nmol} / \mathrm{L}$

AUC $(\text { rat })_{0-6 h}=2.52 \mu \mathrm{M} . \mathrm{h}$

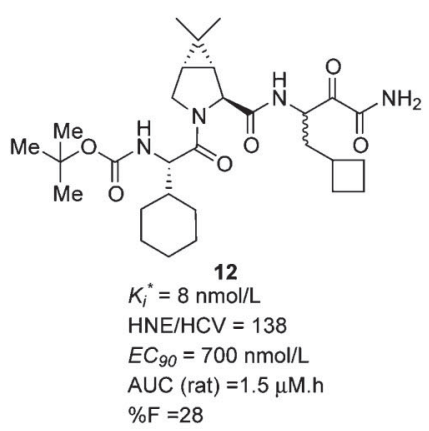

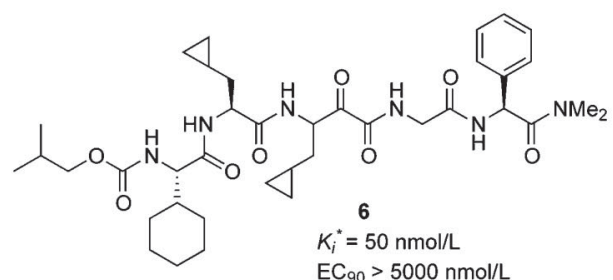

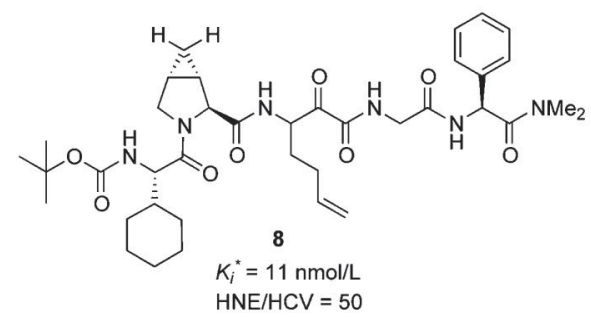

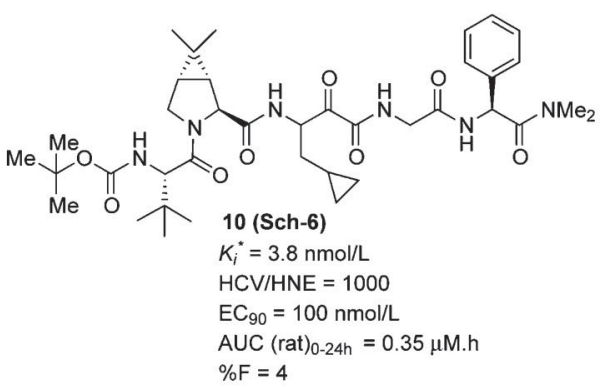

Fig. 4. Structure activity synthesis of boceprevir. 
development, as it contained multiple peptidic bonds derived from natural amino acids, had a high molecular weight, and was metabolically unstable. Although no specific target molecular weight was defined in these studies, general experience suggests that lower molecular weight compounds have improved permeability and tend to be more easily absorbed. Optimization of this undecapeptide initially focused on reducing its molecular weight. The initial SAR was derived primarily through directed combinatorial synthesis and information derived from the NS3 X-ray structure. Highly modified non-proteinogenic amino acids were also introduced in an attempt to improve ligand efficiency and metabolic stability. After considerable optimization, a leucine P2-derived pentapeptide (Analog 5) spanning P3-P2' was identified, which retained significant activity against the NS3 enzyme ( $K{ }^{*} *=$ $630 \mathrm{nmol} / \mathrm{L}$ ) (Fig. 4). This was one of the first analogs to demonstrate potency in the sub-micromolar range. Replacement of leucine with cyclopropylalanine at P2 resulted in Analog 6,which exhibited improved enzyme-binding potency $\left(K i^{*}=50 \mathrm{nmol} / \mathrm{L}\right.$, Fig. 4). ${ }^{29}$

Most of the initial SAR studies during the early stages were guided by enzyme-binding assays because of the lack of robust cellular assays. The introduction of the replicon cellbased assay was pivotal in further refining SAR, and allowed identification of compounds that were active in both binding and cellular assays. Unfortunately, Analog 6 had a halfmaximal effective concentration $\left(\mathrm{EC}_{50}\right)$ of $>5000 \mathrm{nmol} / \mathrm{L}$ in the replicon-based cellular assay, despite its promising enzyme-binding affinity. It was unclear how to interpret these results. One hypothesis was that Analog 6 was polar, containing many amide bonds that prevented it crossing cell membranes. By introducing peptide isosteres, modifying the side chains of amino acids, and methylating amide nitrogens to depeptidize the molecule, the methylated Analog 7 was identified; this demonstrated similar solubility and enzyme activity to Analog $6\left(K^{*}=60 \mathrm{nmol} / \mathrm{L}\right)$ but with much improved cellular activity in the replicon assay $\left(E C_{90}=\right.$ $950 \mathrm{nmol} / \mathrm{L}$ ). Comparison of Analogs 6 and 7 revealed that addition of a secondary amide at P2 yielded compounds that retained good enzyme activity and exhibited favorable potency in the replicon-based cell-culture assay. Further optimization of this secondary amide was investigated via the addition of proline analogs at P2 (Fig. 4).

Cyclization of the $\mathrm{N}$-methyl group to a P2 cyclopropyl group generated the cyclopropylated Analog 8, which had greater enzyme-binding affinity $\left(K^{*}=11 \mathrm{nmol} / \mathrm{L}\right)$ than Analog 6. Introduction of a gem dimethyl group at the cyclopropyl proline resulted in Analog 9, and was associated with improved enzyme-binding affinity and increased potency in the replicon-based cell-culture assay $\left(K i^{*}=1.4 \mathrm{nmol} / \mathrm{L}\right.$; $\left.\mathrm{EC}_{90}=90 \mathrm{nmol} / \mathrm{L}\right) .^{30}$

Having established that Analog 9 showed desirable binding and cellular activities, its oral pharmacokinetics were next evaluated. In rats, administration of Analog $9(10 \mathrm{mg} / \mathrm{kg})$ was associated with poor plasma exposure, with an area under the plasma concentration curve (AUC) of $0.23 \mu \mathrm{mol} / \mathrm{L} /$ $\mathrm{h}$ and oral bioavailability of $1 \%$. These data indicated that the compound was poorly absorbed, suggesting that it was peptidic and needed further reduction in molecular weight. To reduce molecular weight to an acceptable level and improve oral pharmacokinetics, a series of compounds were synthesized that were truncated at $\mathrm{P} 1^{\prime}$ with small groups. Capping compounds similar to Analog 9 at P1' with a primary amide improved oral exposure (Fig. 4).
Truncation of the Analog-9 containing norvaline at $\mathrm{P} 1{ }^{\prime}$ with a primary amide (to produce Analog 11 ) significantly reduced enzyme activity $\left(\mathrm{Ki}^{*}=100 \mathrm{nmol} / \mathrm{L}\right)$. However, this analog had improved oral absorption resulting in increased oral exposure (AUC $=2.52 \mu \mathrm{mol} / \mathrm{L} / \mathrm{h}$ ). Thus, truncating compounds at $\mathrm{P} 1^{\prime}$ as a primary ketoamide improved bioavailability but detrimentally affected binding affinity. Modifications at P1, at P3, and at P3 caps were therefore reconsidered to identify groups that make stronger lipophilic contact with the enzyme, consistent with an improved binding profile. A systematic modification of P1 by the introduction of carbocyclic alanine derivatives led to the discovery of a cyclobutyl methyl group as the optimal P1 moiety based on its excellent contact at the S1 pocket. The resulting Analog 12 exhibited favorable enzyme-binding and cellular activity $\left(\mathrm{Ki}^{*}=8 \mathrm{nmol} / \mathrm{L} ; \mathrm{EC}_{90}=700 \mathrm{nmol} / \mathrm{L}\right)$. In addition, Analog 12 also demonstrated improved oral pharmacokinetics with an AUC of $1.5 \mu \mathrm{mol} / \mathrm{L} / \mathrm{h}$ when administered at a dose of $10 \mathrm{mg} / \mathrm{kg}$. Finally, P3 SAR modifications in combination with changes at the $\mathrm{P} 3$ capping group identified tert-butyl glycine at P3 and tert-butyl urea at the P3 cap, resulting in Analog 13 (SCH503034, boceprevir $)^{31}$; this had improved selectivity against human neutrophil elastase, and retained activity in enzyme and cellular replicon-based assays. The molecular interactions between boceprevir and the NS3/4A protease are depicted in Fig. $5(A, B)$.

\section{In vitro characterization of boceprevir}

Evaluation of boceprevir in the continuous enzyme assay revealed time-dependent inhibition of genotypes 1-6 NS3/4A proteases in a progress curve analysis yielding overall $\mathrm{Ki}$ values of $10-104 \mathrm{nmol} / \mathrm{L}$ (Table 1 ). ${ }^{32-34}$ Since mammalian serine proteases perform many important biological functions, especially in relation to digestion, blood clotting, and complement cascade during antibody neutralization, boceprevir was evaluated against a panel of other human proteases (e.g. human neutrophil elastase, human neutrophil cathepsin G, and human liver cathepsins $H$ and $L$ ). Boceprevir was found to be selective for inhibition of the $\mathrm{HCV}$ protease. A selectivity ratio for the HCV NS3 protease ranging from 4 to $>7000$ was observed when boceprevir was evaluated against a number of human serine and cysteine proteases (Table 1).

In the HCV replicon cell assay, boceprevir potently reduced HCV RNA levels with $E_{50}$ values of $200-400 \mathrm{nmol} / \mathrm{L}$ in genotypes 1,2 , and 5 replicons (Table 1 ). ${ }^{32}$ Incubation of replicon-bearing Huh7 cells for 72 hours with $2.5 \mu \mathrm{mol} / \mathrm{L}$ boceprevir reduced HCV RNA level by 1.5 logs, and prolonged exposure for up to 14 days resulted in replicon RNA levels falling by approximately 4.0 logs, equivalent to $<1$ copy of HCV RNA remaining per cell. ${ }^{32}$ No cytotoxicity was observed in human hepatoma cells or stimulated peripheral blood mononuclear cells.

\section{Preclinical pharmacokinetics and metabolism of boceprevir}

Boceprevir had a favorable oral pharmacokinetic profile based on preclinical in vivo and in vitro evaluations. It was readily absorbed in rats, dogs, and mice, with acceptable plasma exposure, and its bioavailability ranged from $24-34 \%$ with a half-life of 4.2 hours in rats and 1.1 hour in dogs. The compound was found to be partitioned in the liver of rats 
(A)

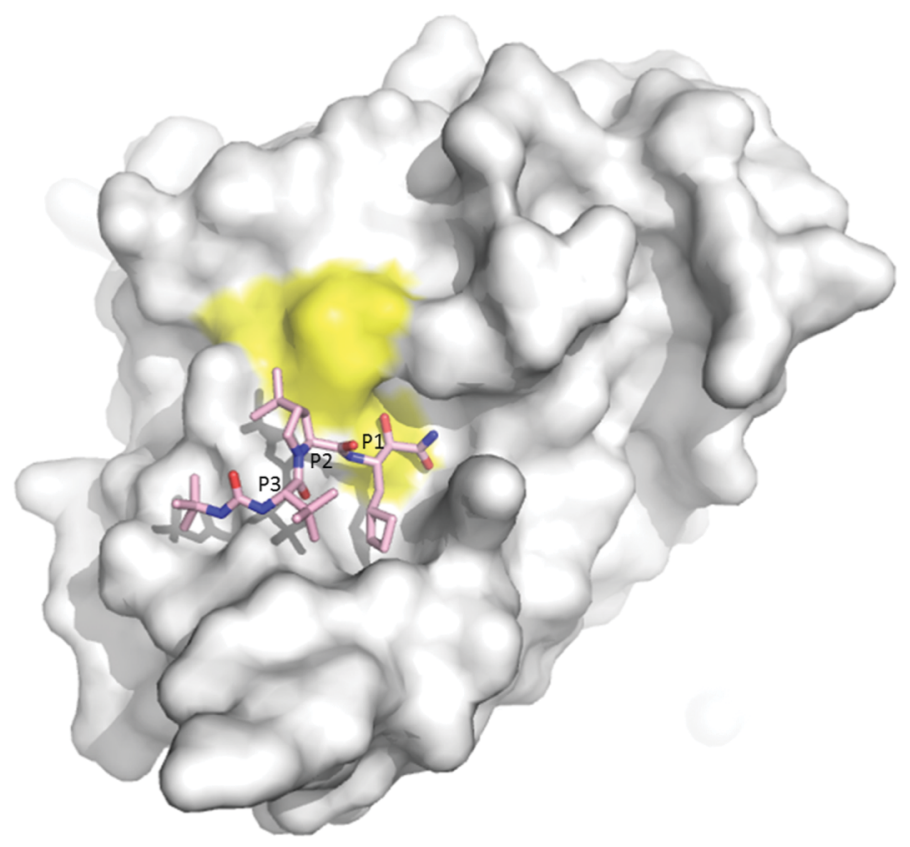

(B)

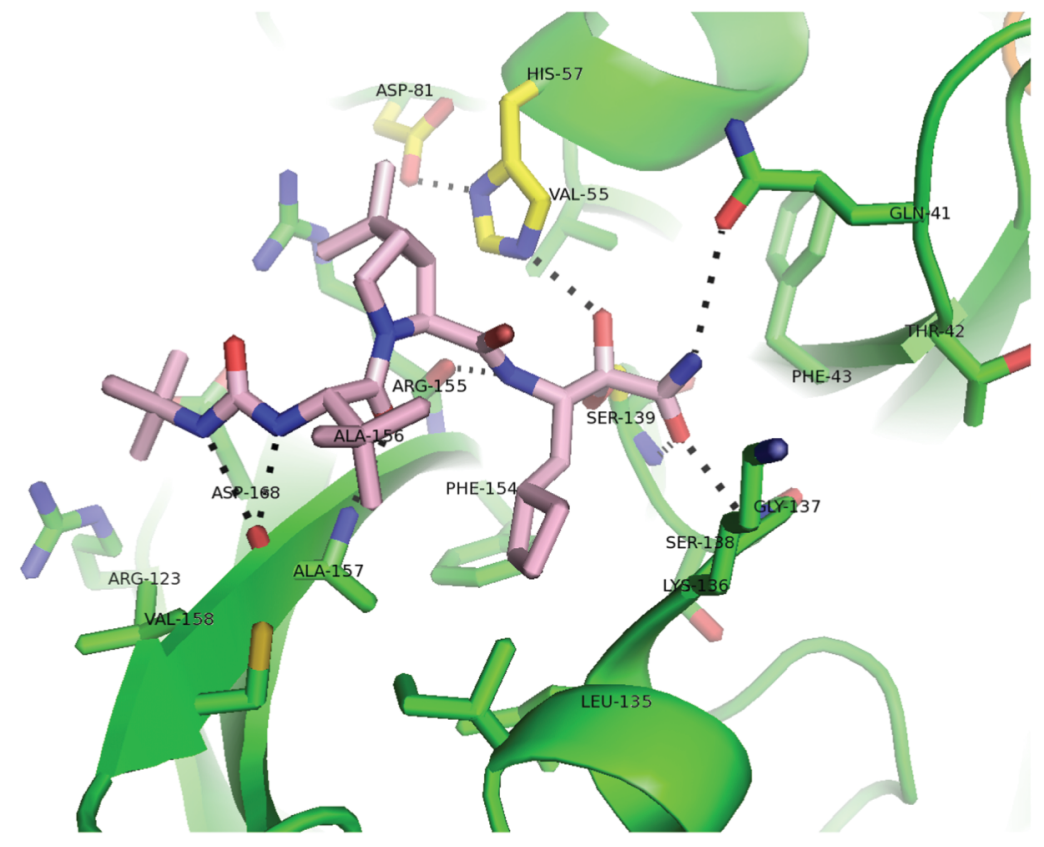

Fig. 5. Boceprevir in complex with NS3/4A. (A) The shallow and solvent-exposed binding groove of NS3/4A is illustrated in the surface diagram. Boceprevir is represented by a ball-and-stick configuration. Approximate locations for the P1-P3 positions are indicated. The residues constituting the catalytic site are shown in yellow. (B) Molecular interactions of boceprevir with amino acid residues within the binding pocket. Amino acids that have backbone and side-chain interactions with boceprevir within $5 \AA$ of the compound binding site are indicated. Within the "oxyanion hole," the backbone and side-chain interactions between the carbonyl oxygen of the amide and $\mathrm{Ser}^{138}$, Gly $^{137}$, and Lys ${ }^{137}$ are indicated.

(liver/plasma ratio of 30). The primary route of metabolism was reduction by aldo-keto reductase (which reduced the ketoamide to hydroxyl amide) and to a lesser extent, oxidation by CYP3A5. Boceprevir did not inhibit cytochrome P450, and was negative in the Ames mutagenicity assay. It was moderately protein-bound in animals, with a human plasma protein binding of $85 \%$. Boceprevir was readily hydrated, and existed as a mixture of two interconvertible diastereomers at $\mathrm{P} 1$ in an approximate $2: 1$ ratio.

\section{Clinical development of boceprevir}

The boceprevir phase III clinical program consisted of two international randomized trials in patients with HCV genotype 
Howe A. Y. M.: Discovery of boceprevir

Table 1. In vitro characteristics and preclinical pharmacokinetics of boceprevir.<smiles>CC(C)(C)NC(=O)N[C@H](C(=O)N1C[C@H]2C[C@H]1C(C(=O)NC(CC1CCC1)C(=O)C(N)=O)C2(C)C)C(C)(C)C</smiles>

Boceprevir (Victrelis)

\begin{tabular}{|c|c|c|}
\hline Chemical name & $\begin{array}{l}\text { ((1R,5S)-N-[3-Amino-1-(cyclobutylme } \\
{[[[(1,1-\text { dimethylethyl)amino]carbonyl }} \\
\text { dimethyl-3-azabicyclo[3.1.0]hexan-2( }\end{array}$ & $\begin{array}{l}\text { xopropyl]-3-[2(S)- } \\
\text { dimethyl-1-oxobutyl]-6,6- } \\
\text { ide) }\end{array}$ \\
\hline Molecular weight & 519.7 & \\
\hline $\mathrm{HCV}$ & NS3/4A enzyme, ${ }^{34} K i^{*} \pm \mathrm{SD}(\mathrm{nmol} / \mathrm{L})$ & Replicon ${ }^{34} \mathrm{EC}_{50^{ \pm}} \mathrm{SD}(\mathrm{nmol} / \mathrm{L})$ \\
\hline GT $1 \mathrm{a}$ & $23 \pm 9(n=18)$ & $236+56(n=21)$ \\
\hline GT $1 b$ & $22 \pm 5(n=20)$ & $219+47(n=16)$ \\
\hline GT 2a & $26 \pm 13(n=6)$ & $317 \pm 31(n=3)$ \\
\hline GT $2 b$ & $6 \pm 1(n=10)$ & $180 \pm 10(n=3)$ \\
\hline GT $3 a$ & $17 \pm 4(n=14)$ & $353 \pm 133(n=3)$ \\
\hline GT 4a & $104 \pm 18(n=18)$ & $\mathrm{n} / \mathrm{a}$ \\
\hline GT 5a & $53 \pm 15(n=12)$ & $250 \pm 78(n=3)$ \\
\hline GT 6a & $10 \pm 2(n=6)$ & $\mathrm{n} / \mathrm{a}$ \\
\hline Therapeutic Index ${ }^{a}$ & \multicolumn{2}{|c|}{$\geqslant 20$} \\
\hline Selectivity Index ${ }^{\mathrm{b}}$ & \multicolumn{2}{|c|}{4 to $\geqslant 7000$} \\
\hline Bioavailability (rat) & \multicolumn{2}{|c|}{$26 \%$} \\
\hline Bioavailability (dog) & \multicolumn{2}{|c|}{$30 \%$} \\
\hline Bioavailability (mouse) & \multicolumn{2}{|c|}{$34 \%$} \\
\hline Bioavailability (monkey) & \multicolumn{2}{|c|}{$4-11 \%$} \\
\hline Liver/plasma ratio (rat) & \multicolumn{2}{|c|}{ Approximately 30 at $10 \mathrm{mg} / \mathrm{kg}$} \\
\hline CYP 2D6, 2C9, 2C19 & \multicolumn{2}{|c|}{$>30 \mu \mathrm{mol} / \mathrm{L}$} \\
\hline CYP $3 A 4$ & $>30 \mu \mathrm{mol} / \mathrm{L}$ & $8.5 \mu \mathrm{mol} / \mathrm{L}$ \\
\hline
\end{tabular}

$\mathrm{CYP}=$ cytochrome P450; GT = genotype; $\mathrm{HCV}$ = hepatitis $\mathrm{C}$ virus; $\mathrm{n} / \mathrm{a}=$ not available.

${ }^{a}$ Ratio of $\mathrm{CC}_{50}$ in Huh7 hepatoma cells or PHA-stimulated PBMC /EC 50 in GT 1 b HCV replicon as measured by Trypan blue viability staining. PHA = phytohemagglutinin; PBMC $=$ peripheral blood mononuclear cell.

${ }^{\mathrm{b}}$ Ratio of $\mathrm{IC}_{50}$ or $K i$ against human serine or cysteine proteases/IC $\mathrm{C}_{50}$ or $K i$ against HCV NS3/4A protease. Human neutrophil elastase, human neutrophil cathepsin $\mathrm{G}_{\text {, human }}$ liver cathepsin $\mathrm{H}$, and human liver cathepsin $\mathrm{L}$ were used in the selectivity studies.

1 infection. Previously untreated patients were enrolled in SPRINT2 ( $n=1097)$ and treatment-experienced patients were enrolled in RESPOND2 $(n=403)$. Each trial included a control arm in which patients received peginterferon plus ribavirin $(P / R)$ for 4 weeks (lead-in) then $P / R$ plus placebo for 44 weeks, and an experimental arm in which patients received $P / R$ lead-in followed by $P / R$ plus boceprevir for 44 weeks. Each trial also included a response-guided therapy (RGT) arm, in which individual treatment duration was tailored based on virologic response. In these studies, treatment with boceprevir significantly improved rates of sustained virologic response (SVR) compared with treatment with $\mathrm{P} / \mathrm{R}$ alone across all patient groups (Table 2)..$^{35,36}$

\section{Lead-in therapy}

In both SPRINT-2 and RESPOND-2, the use of a 4-week leadin phase with $\mathrm{P} / \mathrm{R}$ before the introduction of boceprevir was thought to be associated with several theoretical benefits. $^{35,36}$ The use of P/R to reduce HCV RNA levels before introducing boceprevir may help mitigate the risk of viral breakthrough or resistance, which might otherwise occur with direct antivirals. ${ }^{35}$ In the phase II SPRINT-2 study, use of lead-in therapy was associated with moderately lower rates of virologic breakthrough (defined as a $2 \times \log$ increase in $\mathrm{HCV}$ RNA from nadir and $>50,000 \mathrm{IU} / \mathrm{mL}$ on two consecutive occasions) compared with initiation of treatment with $P / R$ plus boceprevir ( $4 \%$ vs $9 \%, P=0.057$ ). Population sequen- 
Howe A. Y. M.: Discovery of boceprevir

Table 2. Virologic response rates in the boceprevir phase III registration studies SPRINT-2 ${ }^{35}$ and RESPOND-2. ${ }^{36}$

\begin{tabular}{|c|c|c|c|}
\hline Treatment arm & EOTR & Relapse & SVR \\
\hline \multicolumn{4}{|l|}{ SPRINT-2: previously untreated, genotype $1^{35}$} \\
\hline Control arm $(n=363):(P R)_{48}$ & $53 \%(191 / 363)$ & $22 \%(39 / 176)$ & $38 \%(137 / 363)$ \\
\hline RGT $\operatorname{arm}(\mathrm{n}=368)^{\mathrm{a}}$ & $71 \%(261 / 368)$ & $9 \%(24 / 257)$ & $63 \%(233 / 368)$ \\
\hline "Fast responders": $(\mathrm{PR})_{4} /(\mathrm{BPR})_{24}$, total 28 weeks & & & $96 \%(156 / 162)$ \\
\hline "Slow responders": $(P R)_{4} /(B P R)_{24} /(P R)_{20}$, total 48 weeks & & & $72 \%(59 / 82)$ \\
\hline Fixed duration arm $(n=366):(P R)_{4} /(B P R)_{44}$, total 48 wk & $76 \%(277 / 366)$ & $9 \%(24 / 265)$ & $66 \%(242 / 366)$ \\
\hline \multicolumn{4}{|l|}{ RESPOND-2: treatment-experienced, genotype $1^{36}$} \\
\hline Control arm $(n=80):(P R)_{48}$ & $31 \%$ & $32 \%(8 / 25)$ & $21 \%(17 / 80)$ \\
\hline RGT arm $(\mathrm{n}=162)^{\mathrm{b}}$ & $70 \%$ & $15 \%(17 / 111)$ & $59 \%(95 / 162)$ \\
\hline "Fast responders": $(\mathrm{PR})_{4} /(\mathrm{BPR})_{32}$, total 36 weeks & & & $86 \%(64 / 74)$ \\
\hline "Slow responders": $(\mathrm{PR})_{4} /(\mathrm{BPR})_{32} /(\mathrm{PR})_{12}$, total 48 weeks & & & NR \\
\hline PR for 4 wks then $B O C+P R$ for 44 wks $(N=161)$ & $77 \%$ & $12 \%(14 / 121)$ & $66 \%(107 / 161)$ \\
\hline
\end{tabular}

$\mathrm{BOC}=$ boceprevir $(800 \mathrm{mg}$ three times daily with food); EOTR = end of treatment response (defined as undetectable HCV RNA at completion of treatment); PR = peginterferon alfa-2b $(1.5 \mu \mathrm{g} / \mathrm{kg} /$ week) plus ribavirin $(600-1400 \mathrm{mg} /$ day); NR = not reported; SVR = sustained virologic response (defined as undetectable HCV RNA 24 weeks after completion of treatment); RGT = response-guided therapy.

a In the RGT arm in SPRINT-2, "fast responders" were subjects with undetectable HCV RNA during weeks 8-24 were treated for a total duration of 28 weeks (24 weeks of boceprevir-containing therapy), while "slow responders" were subjects with detectable HCV RNA at any visit between weeks 8 and 24 (but not including week 24 ), and these were treated for a total duration of 48 weeks ( 24 weeks of boceprevir-containing therapy). In all treatment arms, subjects with detectable HCV RNA at week 24 were withdrawn from treatment.

bIn the RGT arm in RESPOND-2, "fast responders" were subjects with undetectable HCV RNA at week 8 and 12 , and these completed therapy at week 36 (including 32 weeks of boceprevir-containing therapy), while "slow responders" were subjects with detectable HCV RNA at week 8 but undetectable HCV RNA at week 12 , and these received an additional 12 weeks of therapy with peginterferon + ribavirin for a total treatment duration of 48 weeks (including 32 weeks of boceprevir-containing therapy). In all treatment arms in RESPOND-2, subjects with detectable HCV RNA at week 12 had therapy discontinued.

cing revealed that the major variants, occurring in $>25 \%$ of samples, were V36M, T54S, and R155K. ${ }^{37}$ In this study, 63 of $144(44 \%)$ patients who underwent post-baseline sampling developed resistance-associated variants while receiving boceprevir, with the most frequently reported variants being R155K, V36M, and T54S in patients with G1a infection, and T54S, T54A, A156S, and V170A in patients with G1b infection. ${ }^{38}$

Lead-in therapy is also associated with a number of other theoretical benefits. Ribavirin requires approximately 4 weeks to reach steady-state concentrations, and has a plasma half-life of 298 hours with multiple dosing. ${ }^{39}$ The 4week lead-in period therefore ensures that the antiviral effects of ribavirin are maximized before introduction of boceprevir. In addition, lead-in therapy also allows for the assessment of IFN responsiveness before boceprevir administration. Patients without a robust response to $P / R$ may be considered at higher risk for viral breakthrough, and therefore require closer monitoring.

In both SPRINT-2 and RESPOND-2, a decline in HCV RNA of $<1 \log$ at the end of the lead-in period was associated with substantially lower rates of SVR compared with good IFN response ( $\geqslant 1 \log$ decline at week 4 ). Multivariate logistic regression analyses of the data from these studies suggest that interleukin-28B genotype is a significant baseline predictor of IFN responsiveness, confirming that underlying IFN response remains a critical component affecting clinical outcomes in patients receiving boceprevir-containing regimens. ${ }^{40}$

\section{Response-guided therapy with boceprevir}

Both SPRINT-2 and RESPOND-2 included an RGT treatment arm, in which treatment duration was tailored according to virologic response milestones while on treatment. ${ }^{35,36}$ The objective of this approach was to minimize treatment duration and thereby limit drug exposure and treatmentrelated adverse events. In SPRINT-2, 44\% (162/368) of patients randomized to RGT were eligible for the reduced treatment duration, and of these 96\% (156/162) achieved SVR. ${ }^{35}$ Similarly, in RESPOND-2, 46\% (74/162) of patients randomized to RGT were eligible for reduced treatment duration, and the SVR rate in this cohort was 86\% (64/ 74). ${ }^{36}$ Thus, in both SPRINT- 2 and RESPOND-2, $>40 \%$ of subjects enrolled in the RGT arms received a reduced treatment duration without any impact on SVR rates. RGT has now been adopted as the recommended treatment approach with boceprevir, with week 8 of therapy being the key decision point used to define treatment duration. ${ }^{41}$

\section{Conclusions}

Boceprevir in combination with $\mathrm{P} / \mathrm{R}$ significantly increases the rates of SVR compared with $\mathrm{P} / \mathrm{R}$ alone, with an approximate two-fold improvement in SVR in previously untreated patients, and approximate three-fold improvement in treatment-experienced patients. ${ }^{35,36}$ These improved clinical outcomes for patients with HCV represent a significant advance in the treatment of $\mathrm{HCV}$, and have been derived from efforts to understand the pathophysiology of $\mathrm{HCV}$, and the molecular virology and biochemistry of HCV replication processes. The advances in the basic science of HCV made during the past 2 decades will continue to bear fruit as second- and thirdgeneration direct-acting antiviral agents undergo clinical evaluation both in conjunction with IFN and in combination as IFN-free regimens. It is hoped that these next generations of antivirals will offer pan-genotype activity with shorter 
treatment duration, and meet the ultimate goal of IFN-free regimens for all patients.

\section{Conflict of interest}

AYMH and SV are employees of Merck Research Laboratories, Kenilworth, NJ

\section{Author contributions}

Manuscript writing (AYMH, SV).

\section{Acknowledgments}

We thank Dr. Bruce Malcolm for the insightful discussions, Dr. Daria Hazuda for the critical review of the manuscript, and Drs. Charles Lesburg, Zhuyan Guo, Rumin Zhang, and Frederick Lahser for providing the crystal structure diagrams and biochemical results. We also thank colleagues from Schering-Plough and Merck Research Laboratories for generating the data and for their helpful comments. Finally, we thank all the investigators and patients who participated in the clinical development of boceprevir. Medical writing and editorial assistance were provided by Tim Ibbotson, PhD, Santo D'Angelo, PhD, MS, and Bianca Ruzicka, PhD of ApotheCom, Yardley, PA. This assistance was funded by Merck Sharp \& Dohme Corp., a subsidiary of Merck \& Co., Inc., Whitehouse Station, NJ.

\section{References}

[1] Lavanchy D. Evolving epidemiology of hepatitis C virus. Clin Microbiol Infect 2011;17:107-115.

[2] Moradpour D, Penin F, Rice CM. Replication of hepatitis C virus. Nat Rev Microbiol 2007;5:453-463.

[3] Rice CM. New insights into HCV replication: potential antiviral targets. Top Antivir Med 2011;19:117-120.

[4] Kim JL, Morgenstern KA, Lin C, Fox T, Dwyer MD, Landro JA, et al. Crystal structure of the hepatitis C virus NS3 protease domain complexed with a synthetic NS4A cofactor peptide. Cell 1996;87:343-355.

[5] Yan Y, Li Y, Munshi S, Sardana V, Cole JL, Sardana M, et al. Complex of NS3 protease and NS4A peptide of BK strain hepatitis $C$ virus: a 2.2 A resolution structure in a hexagonal crystal form. Protein Sci 1998; 7:837-847.

[6] Yao N, Reichert P, Taremi SS, Prosise WW, Weber PC. Molecular views of vira polyprotein processing revealed by the crystal structure of the hepatitis $C$ virus bifunctional protease-helicase. Structure 1999;7:1353-1363.

[7] Kim DW, Gwack Y, Han JH, Choe J. Towards defining a minimal functional domain for NTPase and RNA helicase activities of the hepatitis C virus NS3 protein. Virus Res 1997;49:17-25.

[8] Love RA, Parge HE, Wickersham JA, Hostomsky Z, Habuka N, Moomaw EW, et al. The conformation of hepatitis C virus NS3 proteinase with and without NS4A: a structural basis for the activation of the enzyme by its cofactor. Clin Diagn Virol 1998;10:151-156.

[9] Bartenschlager R, hlborn-Laake L, Mous J, Jacobsen H. Kinetic and structura analyses of hepatitis C virus polyprotein processing. J Virol 1994;68:50455055

[10] Di Marco S., Rizzi M, Volpari C, Walsh MA, Narjes F, Colarusso S, et al. Inhibition of the hepatitis $C$ virus NS3/4A protease. The crystal structures of two protease-inhibitor complexes. J Biol Chem 2000;275:71527157.

[11] Barrett AJ. An introduction to the proteases. In: Barrett AJ, Salveson G, eds. Proteinase Inhibitors. New York, NY: Elsevier; 1986:22.

[12] Raney KD, Sharma SD, Moustafa IM, Cameron CE. Hepatitis C virus nonstructural protein 3 (HCV NS3): a multifunctional antiviral target. J Biol Chem 2010;285:22725-22731.

[13] Steinkuhler C, Biasiol G, Brunetti M, Urbani A, Koch U, Cortese R, et al. Product inhibition of the hepatitis C virus NS3 protease. Biochemistry 1998; 37:8899-8905.
[14] Steinkuhler C, Urbani A, Tomei L, Biasiol G, Sardana M, Bianchi E, et al. Activity of purified hepatitis C virus protease NS3 on peptide substrates. J Virol 1996;70:6694-6700

[15] Xue W, Wang $M$, Jin X, Liu $H$, Yao X. Understanding the structural and energetic basis of inhibitor and substrate bound to the full-length NS3/4A: insights from molecular dynamics simulation, binding free energy calculation and network analysis. Mol Biosyst 2012;8:2753-2765.

16] Xue $W$, Pan $D$, Yang $Y$, Liu $H$, Yao $X$. Molecular modeling study on the resistance mechanism of $\mathrm{HCV}$ NS3/4A serine protease mutants R155K, A156V and D168A to TMC435. Antiviral Res 2012;93:126-137.

[17] Llinas-Brunet M, Bailey M, Fazal G, Ghiro E, Gorys V, Goulet S, et al. Highly potent and selective peptide-based inhibitors of the hepatitis $C$ virus serine protease: towards smaller inhibitors. Bioorg Med Chem Lett 2000;10:22672270.

[18] Pessi A. A personal account of the role of peptide research in drug discovery: the case of hepatitis C. J Pept Sci 2001;7:2-14.

[19] Sali DL, Ingram R, Wendel M, Gupta D, McNemar C, Tsarbopoulos A, et al. Serine protease of hepatitis $C$ virus expressed in insect cells as the NS3/4A complex. Biochemistry 1998;37:3392-3401.

[20] Shoji I, Suzuki T, Chieda S, Sato M, Harada T, Chiba T, et al. Proteolytic activity of NS3 serine proteinase of hepatitis $C$ virus efficiently expressed in Escherichia coli. Hepatology 1995;22:1648-1655.

[21] Butkiewicz NJ, Wendel M, Zhang R, Jubin R, Pichardo J, Smith EB, et al. Enhancement of hepatitis $C$ virus NS3 proteinase activity by association with NS4A-specific synthetic peptides: identification of sequence and critical residues of NS4A for the cofactor activity. Virology $1996 ; 225: 328$ 338.

[22] Taremi SS, Beyer B, Maher M, Yao N, Prosise W, Weber PC, et al. Construction, expression, and characterization of a novel fully activated recombinant single-chain hepatitis C virus protease. Protein Sci 1998;7 2143-2149.

[23] Williams JW, Morrison JF. The kinetics of reversible tight-binding inhibition. Methods Enzymol 1979;63:437-467

[24] Morrison JF, Walsh CT. The behavior and significance of slow-binding enzyme inhibitors. Adv Enzymol Relat Areas Mol Biol 1988;61:201-301.

[25] Zhang R, Beyer BM, Durkin J, Ingram R, Njoroge FG, Windsor WT, et al. A continuous spectrophotometric assay for the hepatitis $C$ virus serine protease. Anal Biochem 1999;270:268-275.

[26] Lohmann V, Korner F, Koch J-O, Herian U, Theilmann L, Bartenschlager R. Replication of subgenomic hepatitis $C$ virus RNAs in a hepatoma cell line. Science 1999;285:110-113.

[27] Guo JT, Bichko VV, Seeger C. Effect of alpha interferon on the hepatitis C virus replicon. J Virol 2001;75:8516-8523.

[28] Lohmann V, Korner F, Dobierzewska A, Bartenschlager R. Mutations in hepatitis C virus RNAs conferring cell culture adaptation. J Virol 2001;75:1437-1449.

[29] Bogen SL, Saksena AK, Arasappan A, Gu H, Njoroge FG, Girijavallabhan V, et al. Hepatitis C virus NS3-4A serine protease inhibitors: use of a P2-P1 cyclopropyl alanine combination for improved potency. Bioorg Med Chem Lett 2005;15:4515-4519.

[30] Bogen SL, Arasappan A, Bennett F, Chen K, Jao E, Liu YT, et al. Discovery of SCH446211 (SCH6): A new ketoamide inhibitor of the HCV NS3 serine protease and HCV subgenomic RNA replication. J Med Chem 2006;49:27502757.

31] Venkatraman $S$, Bogen $S L$, Arasappan $A$, Bennett $F$, Chen $K_{\text {, Jao }} E_{\text {, et al. }}$. Discovery of (1R,5S)-N-[3-amino-1-(cyclobutylmethyl)-2,3-dioxopropyl] 3-[2(S)-[[[(1,1-dimethylethyl)amino]carbonyl]amino]-3,3-dimethyl-1oxobutyl]- 6,6-dimethyl-3-azabicyclo[3.1.0]hexan-2(S)-carboxamide ( $\mathrm{SCH} 503034)$, a selective, potent, orally bioavailable hepatitis $\mathrm{C}$ virus NS3 protease inhibitor: a potential therapeutic agent for the treatment of hepatitis C infection. J Med Chem 2006;49:6074-6086.

[32] Malcolm BA, Liu R, Lahser F, Agrawal S, Belanger B, Butkiewicz N, et al. SCH 503034, a mechanism-based inhibitor of hepatitis C virus NS3 protease, suppresses polyprotein maturation and enhances the antiviral activity of alpha interferon in replicon cells. Antimicrob Agents Chemother 2006;50: 1013-1020.

[33] Zhang R, Windsor WT. In vitro kinetic profiling of HCV NS3 inhibitors by progress curve analysis. Book chapter (in preparation).

[34] Howe JA, Graham D, McMonagle P, Curry S, Chase R, Lahser F, et al. In-vitro characterization of the pan-genotype activity of the HCV NS3/4A protease inhibitors boceprevir and teleprevir. Poster presented at the 47th Annual Meeting of the European Association for the Study of the Liver, Barcelona, Spain, April 18-22, 2012.

[35] Poordad F, McCone ], Bacon BR, Bruno S, Manns MP, Sulkowski MS, et al. Boceprevir for untreated chronic HCV genotype 1 infection. New Engl ] Med 2011;364:1195-1206.

[36] Bacon B, Gordon SC, Lawitz E, Marcellin P, Vierling JM, Zeuzem S, et al. Boceprevir for previously treated chronic HCV genotype 1 infection. New Eng J Med 2011;364:1207-1217.

[37] Kwo PY, Lawitz EJ, McCone J, Schiff ER, Vierling JM, et al. Efficacy of boceprevir, an NS3 protease inhibitor, in combination with peginterferon alfa- 
Howe A. Y. M.: Discovery of boceprevir

$2 \mathrm{~b}$ and ribavirin in treatment-naive patients with genotype 1 hepatitis $\mathrm{C}$ infection (SPRINT-1): an open-label, randomised, multicentre phase 2 trial. Lancet 2010;376:705-716.

[38] Ogert RA, Howe JA, Vierling JM, Kwo PY, Lawitz EJ, McCone J, et al. Resistance-associated amino acid variants associated with boceprevir plus pegylated interferon- $\alpha 2 \mathrm{~b}$ and ribavirin in patients with chronic hepatitis $\mathrm{C}$ in the SPRINT-1 Trial. Antivir Ther 2013;18:387-397.
[39] Schering-Plough. Rebetol ${ }^{\mathbb{R}}$ (ribavirin UPS) capsules, oral solution. 2009. Kenilworth, NJ, Schering Plough.

[40] Poordad F, Bronowicki JP, Gordon SC, Zeuzem S, Jacobson IM, Sulkowski MS, et al. Factors that predict response of patients with HCV Infection to boceprevir. Gastroenterology 2012;143:608-618.

[41] Merck \& Co., Inc. VICTRELIS ${ }^{\infty}$ (boceprevir) capsules. 2011. Whitehouse Station, NJ, Merck \& Co., Inc. 